\title{
BIEN COMÚN E INTERÉS PÚBLICO EN EL PENSAMIENTO DE ALASDAIR MACINTYRE
}

CONSIDERACIONES A PROPÓSITO DE UN TEXTO INÉDITO

COMMON GOOD AND PUBLIC INTEREST IN ALASDAIR MACINTYRE

considerations on purpose of an unpublished text

\section{BEM COMUM E INTERESSE PÚBLICO NO PENSAMENTO DE ALASDAIR MACINTYRE}

considerações a propósito de um texto não publicado

\author{
Rivas Pedro \\ (Universidad de A Coruña) \\ pedro.rivas@udc.es
}

Recibido: 03/06/2020

Aprobado: 03/08/2020

\begin{abstract}
RESUMEN
Aunque las obras principales de MacIntyre son muy conocidas, existe un texto inédito que rara vez suele encontrarse citado y que es relevante para comprender sus tesis acerca de la Política. El texto recoge con mayor detalle, que en otros lugares de la obra del pensador escocés, sus tesis acerca del bien común. El propósito de este trabajo es exponer dichas tesis, completándolas con otros artículos de MacIntyre sobre la misma temática, para dar un cuadro más exacto de su pensamiento sobre el bien común. Al hilo de tal exposición se lleva a cabo una serie de comentarios que surgen de su lectura.

Palabras clave: Bien común. Interés público. MacIntyre.

\section{ABSTRACT}

Although MacIntyre's main works are well known, there is an unpublished text that is rarely quoted and is relevant to understanding his theses on Politics. The text contains in greater detail than elsewhere in the MacIntyre's work his theses on the common good. The purpose of this work is to set out these theses, complementing them with other articles by MacIntyre on the same subject, to give a more exact picture of his vision on the common good. In the wake of this presentation, a series of comments are made that arise from reading it.
\end{abstract}

Keywords: Common Good. Public Interest. MacIntyre.

\section{RESUMO}

Embora os principais trabalhos de MacIntyre sejam bem conhecidos, há um texto inédito que raramente é citado e que é relevante para a compreensão de suas teses sobre Política. O texto contém em maior detalhe do que em qualquer outro trabalho do pensador escocês, suas teses sobre o bem comum. O objetivo deste trabalho é apresentar estas teses, 
completando-as com outros artigos de MacIntyre sobre o mesmo assunto, para dar uma imagem mais exata de seu pensamento sobre o bem comum. Após esta exposição, são feitos uma série de comentários que surgem de sua leitura.

Palavras-chave: Bem Comum. Interesse Público. MacIntyre.

\section{Introducción}

La bibliografía sobre MacIntyre es muy numerosa y crece sin parar. Además, sus obras principales son bastante conocidas, al punto que algunas se consideran clásicos del pensamiento contemporáneo. Sin embargo, existe un texto inédito que rara vez suele encontrarse citado (como excepción, puede verse Ramis Barceló, 2012) y que por su contenido es relevante en sí mismo, y para comprender las tesis de MacIntyre acerca de la Política. Se trata de las Agnes Cuming Lectures in Philosophy, impartidas en el University College de Dublin los días 1, 2 y 3 de marzo de 1994, con el título Laws, Goods and Virtues: Medieval Resources for Modern Conflicts. La primera de ellas, titulada Natural Law as Subersive: the case of Aquinas fue publicada dos años después con el mismo título en el volumen 26 del Journal of Medieval and Early Modern Studies. Sin embargo, la segunda y la tercera de las lectures permanecen inéditas. La segunda de ellas lleva por título Natural law against the nation-state: or the possibility of the common good against the actuality of the public interest (MacIntyre, 1994a). La tercera se titula The Virtues of Practice Against the Efficiency of Institutions (MacIntyre, 1994b). A mi modo de ver, la relevancia estriba en que recogen con mayor detalle sus tesis acerca del bien común, que en otros lugares de la obra del pensador escocés. El propósito de este trabajo es, en primer lugar, exponer las tesis de tales conferencias, al mismo tiempo que se completan con otros artículos de MacIntyre sobre la propia temática, para tratar de dar un cuadro más exacto de su pensamiento sobre el bien común. Al hilo de tal exposición se lleva a cabo una serie de comentarios que surgen de la lectura de ambas conferencias. Por mor del espacio disponible, voy a centrar mis comentarios en la crítica que hace el autor respecto a la idea de interés público como concepto que estructura las comunidades políticas modernas.

Con todo, se debe hacer una referencia a la primera de las tres conferencias, la cual fue publicada posteriormente. En ella se lleva a cabo una aproximación histórica en la que se muestra que la perspectiva tomista con respecto al Derecho es la misma que la de los romanistas, en contraposición a la concepción de la relación del gobernante con el Derecho que tienen algunos de sus contemporáneos, como Luis IX de Francia o Federico II de Sajonia (MacIntyre, 1996: 61-83). La explicación tomista se comprende bien si, por un lado, se sitúa en la discusión entre quienes defienden que quien detenta el poder soberano es no sólo el que promulga sino el que crea y recrea el Derecho, y restringe el conocimiento del Derecho a expertos operadores autorizados por el soberano. Y por otro lado, quienes como el Aquinate, sostienen que los preceptos y principios del Derecho tienen autoridad antes de su promulgación por cualquier poder soberano y el conocimiento de tales preceptos y principios pertenece a toda persona racional común (MacIntyre, 1994b: 53).

La posición que MacIntyre personaliza en las personas de ambos reyes no es sino un precedente (con otras muchas diferencias relevantes) de las tesis políticas acerca de la soberanía formuladas con toda precisión siglos después. En efecto, la idea de soberanía significa ante todo el sometimiento del Derecho al poder político al comprender este último como el monopolio de las fuentes del Derecho. Este proceso se cristaliza en el siglo XIX con el movimiento codificador (Bobbio, 1979: capítulo III). La contraposición que muestra MacIntyre le sirve para poder ubicar la visión aristotélica y tomista de la comunidad política frente a la visión moderna, uno de cuyos antecedentes sería esa concepción de los reyes medievales que describe.

A mi juicio, las otras dos conferencias, las que se consideran en este trabajo, pueden ser tratadas aparte de la primera. En ambas, el elemento clave es la comprensión de una sociedad estructurada a partir del bien común, cuestión que se lleva a cabo en primer lugar mediante la comparación de este género de sociedades con las que se estructuran a partir de la idea de interés público, como ocurre en el Estado 
liberal presente. En segundo lugar, afronta una crítica de estas últimas a la par que defiende el carácter no utópico de las primeras.

\section{Dos formas de comunidad}

Como se ha dicho, mostrar en qué consiste una comunidad estructurada en la idea de bien común, se lleva a cabo a través de la comparación con una comunidad estructurada a partir de la idea de interés público. Vamos a afrontarlo a partir de las diferencias que el propio MacIntyre señala entre ambos géneros de comunidades.

\subsection{La justificación política}

Hay que señalar el modo diverso de justificar políticamente cada tipo de comunidad. Esta diferencia le sirve para dar una explicación primaria de cada uno. Entiende por justificación política los argumentos que muestran por qué debemos, o no, aceptar como teniendo autoridad política los mandatos o las leyes de quien reclama autoridad ejecutiva o legislativa (MacIntyre, 1997: 242).

Para entender una comunidad estructurada por el bien común, se hace necesario en primer lugar caracterizar qué se entiende por bien común. Para ello señala seis rasgos que pertenecen a la esencia del bien común:

A) Se trata del bien de un tipo de asociación.

B) No se reduce a los bienes de los miembros individuales de tal asociación.

C) No se construye al margen de los bienes de los miembros individuales.

D) Es parte de y en parte constituye los bienes de cada miembro individual.

E) No toda asociación tiene un bien común porque puede constituirse con otros fines. En este aspecto la existencia de comunidades estructuradas conforme al interés público son ejemplos de lo que se sostiene.

F) Los fines perseguidos para lograr un bien común sólo se alcanzan por individuos que actúan como partes de un todo comunitario, y que implícita o explícitamente comprenden su bien individual como constituido en parte por un bien o bienes caracterizables independiente y antecedentemente a la caracterización de su bien individual particular (MacIntyre, 1994a: 27).

La noción de bien común de los que se asocian para lograr los fines de una actividad en particular es inseparable de las nociones de recto orden de la actividad y de bien común que consiste en lograr los fines a los que se ordena la actividad. ¿Qué tipo de actividad política resulta si se ordena de este modo tal actividad? Una actividad a través de la cual una comunidad ordena la variedad de prácticas e instituciones comprometidas en y sostenidas por sus miembros. El bien específico de una actividad política así consistiría en el vivir cooperativo de un tipo particular de vida en común, en la que la variedad de bienes prácticos tiene su lugar ordenado: se trata de un bien distintivo sin el cual los otros no se pueden lograr (MacIntyre, 1994a: 28). Para una visión aristotélica y tomista sólo podemos entender el derecho a la luz del bien. De ahí que el acuerdo racional sobre las reglas morales presupone un acuerdo racional sobre la naturaleza del bien humano (MacIntyre, 1990: 344-345).

En cambio, cuando lo que estructura es el interés público, entonces la comunidad política es un escenario o estadio (arena) donde los individuos y grupos persiguen intereses privados y tienen también un interés común. El éxito de una política interesa solamente si afecta la satisfacción de las preferencias particulares. El interés común de un grupo existe en la medida en que afecta las preferencias de sus miembros. La justificación de la asociación reside en lograr un marco institucional que los individuos tienen interés en sostener. La expresión política de los bienes que cada uno persigue se entenderá siempre en términos de preferencias e intereses. Todo esto es característico de los estados contemporáneos, que incorporan entonces la aspiración a la neutralidad e imparcialidad con respecto a 
las pretensiones rivales sobre el bien y los bienes, tratando a estos bienes como expresión de preferencias e intereses (MacIntyre, 1994a: 28-29).

A mi juicio, desde la perspectiva recién descrita, carece de sentido pretender que exista un bien común político. El bien es siempre particular. Lo más parecido a un bien común es la maximización de los bienes particulares coincidentes. Pero esos bienes no son propiamente comunes sino singulares y coincidentes, es decir, tenemos por bienes particulares realidades similares, o apreciamos como buenos los mismos bienes particulares. Pero el carácter de bondad de una realidad es siempre individual, singular, particular. El sentido de nuestras comunidades políticas es la protección de los bienes particulares y nada más.

De ahí, la ausencia de algo verdaderamente común en el interior de la comunidad política. Aunque todos los individuos posean su persona y sus capacidades de manera igual, esto no significa que exista nada común entre ellos. Al contrario, todo se posee con el único fin de competir, de aumentar lo poseído por los demás. De este modo, si no hay nada realmente común, es difícil encontrar la propia identidad en la sociedad en la que uno se encuentra.

En un trabajo anterior, MacIntyre hace una reflexión que profundiza más en lo dicho. Y es que los desacuerdos sobre el bien humano son numerosos y fundamentales: se da un divorcio entre reglas por un lado y concepciones del bien humano por otro. Para el pensamiento liberal (que se identifica con la concepción de la comunidad estructurada por el interés público), las instituciones públicas deben ser neutrales entre concepciones rivales del bien humano. La lealtad a una particular concepción del bien es cuestión de elección privada. El acuerdo requerido y el desacuerdo permitido sobre concepciones del bien se caracterizan por su comprensión de la relación entre libertad y razón: la autonomía del individuo racional se ejerce aceptando una de las visiones en disputa. Por tanto, elaborar, defender y vivir según una particular concepción del bien se restringe a la vida privada, mientras en lo público se debate sobre la obediencia a reglas morales para cada persona racional (MacIntyre, 1990: 346). De este modo, la privatización del bien asegura no sólo que carecemos de reglas morales compartidas adecuadamente determinadas, sino que elementos centrales de carácter moral no pueden llegar a ser objeto de discurso o de indagación sistemática y pública compartida (MacIntyre, 1990: 353).

Desde mi punto de vista, la pertenencia del hombre a la sociedad no tiene una finalidad relacionada con el perfeccionamiento o bien propio del hombre. Lo que está detrás no es sino una comprensión del hombre que en el fondo resulta ser vacía. Paralelamente el hombre que se reúne en sociedad sigue careciendo de fines más allá de su permanencia en el ser (Hobbes, 2014: I, 14; Spaemann, 1980: 202). En nuestra opinión, la pérdida de la noción de finalidad a la hora de hablar del hombre y de su libertad conlleva a un empobrecimiento en el momento de concebir el hecho social porque éste en último término también es un hecho humano. En la sociedad, tal y como se concibe el hombre, no puede reconocerse, sólo puede sobrevivir. La ley posee una justificación funcional exclusivamente por referencia a la supervivencia humana pero no parece ni de lejos uno de los elementos básicos para el correcto desarrollo de la vida humana. La consecuencia inmediata es la concepción de la ley como mero límite; fundamental para sobrevivir, pero límite, al fin y al cabo, y como tal dotado de una fuerte carga negativa. Ahora la ley se "justifica” en el sentido más pobre de la palabra: no queda más remedio que vivir bajo la ley. Por tanto, lo positivo del hombre vendría a ser todo aquello que pudiera desarrollarse al margen de ella. En este sentido se entiende el carácter meramente instrumental de la comunidad política para la mentalidad moderna. La comunidad política, ahora el Estado, no añade nada al individuo singular en cuanto a sus fines: se pretende que no sea más que un simple medio eficiente. Pero, al mismo tiempo, se trata de un medio con vida propia y que es capaz de invertir la relación, es decir, de convertir al individuo en medio para sus fines.

Más recientemente, MacIntyre ha insistido en que los desacuerdos morales en nuestras sociedades contemporáneas son irresolubles. La diferencia de tales desacuerdos cuando se daban en sociedades anteriores radica en que quienes ahora toman parte en ellos parecen presuponer la apelación a algún estándar impersonal al que referir los desacuerdos. Pero a la vez son conscientes de manera evidente 
de que no hay esperanza de que las convicciones de sus oponentes cambien por argumentos racional, lo que significa que no hay tal estándar (MacIntyre, 2008: 262).

\subsection{El modo de entenderse en comunidad}

A partir de lo anterior, se comprende el modo de entenderse en el interior de una comunidad. Para quienes defienden una comunidad estructurada a partir del bien común, el autogobierno de la comunidad se ejercita a través de unas actividades y una participación que es necesaria para que cada ciudadano logre su propio bien. Los fines de la actividad política son entendidos como internos a los fines individuales. El yo se constituye en parte a través de su actividad política y un yo sin tal actividad sería un yo carente, indigente. Hablar de bien común no niega la diferencia entre público y privado, sino que ubica tal diferencia en otro lugar, porque el yo es miembro también de comunidades más inmediatas que son independientes de y a la vez contribuyen a la comunidad política: el yo individual es más que sus actividades políticas.

Para quienes sostienen una comunidad política estructurada a partir de la idea de interés público, el Estado es una agencia o grupo de agencias externo a ellos y a sus intereses privados. Incluso si ocupan papeles políticos, tal cuestión no constituye su identidad moral ni política. Por lo anterior, hablar de bien común no solamente es metafísico sino peligroso (MacIntyre, 1994a: 30). En efecto, el grado de identificación de un individuo moderno con la comunidad en que vive es condicional. Sólo en la medida en que satisfaga las condiciones prescritas por su particular concepción de los derechos, habrá una buena razón para identificarse. Lealtad familiar y patriotismo se ponen en cuestión (MacIntyre, 1991: 105).

A mi modo de ver, como toda realidad compuesta de seres vivos, el Estado pareciera tener también vida propia (Cruz Prados, 2009: passim). Al pensarse a sí mismo como una realidad previa, el individuo singular tiene la consideración de lo otro (en este caso el Estado) como peligro, o incluso enemigo, por el simple motivo de que no parece posible reconocerse en él sino sólo en mí mismo. Para la mentalidad moderna que tiene por centro el valor de la autonomía de la voluntad, la propia realidad, la propia identidad, donde uno se reconoce, es apenas en sí mismo y con dificultad en algunos de sus semejantes. De modo que si tengo dificultad para reconocerme en el otro, mucho menos voy a reconocerme en una realidad posterior que viene a pretender ser la suma de todos. Esa realidad otra, que llamamos comunidad política y que adopta ahora los caracteres del Estado, es si cabe peor porque es más grande y fuerte que uno. Y está, eso sí, tan viva como uno, porque está formada por seres humanos. Así, ese otro es una realidad viva, que opera con mayor fuerza que un ser humano y que carece precisamente de aquello que puede hacer que uno se reconozca en él. Por eso, el afán cada vez mayor del ser humano ha sido no sólo evitar ser dominado por el Estado, sino también tratar de dominarlo a él para emplear precisamente toda su fuerza.

La comunidad política en forma de Estado se presenta entonces como una estructura artificial que consiste fundamentalmente en poder. $\mathrm{Y}$ un poder que entra en inevitable conflicto con la realidad previa que es el individuo y sus derechos. Lo político es algo a lo que nos vemos abocados a regañadientes y en este repliegue del individuo sobre sí mismo, lo comunitario se ve siempre como peligroso, no identitario, ajeno. No es que se haya alejado del sujeto singular, sino que estaba lejos desde el principio. El impulso lleva a alejarse de esa construcción peligrosa donde uno no puede reconocerse porque no sirve a, sino que conspira contra el propio proyecto vital. En el fondo, parece latir una ilusión de una especie de cielo en la tierra compuesto por el individuo solo, pleno de derechos frente a ningún otro, rodeado de todos los bienes de la tierra, a los que tal vez añadir otros individuos en la medida en que se comporten como bienes.

Lo anterior explica también que el contenido del pensamiento político a partir de la modernidad ha sido precisamente el poder. Porque ahora en el origen de lo político no hay sino un acto de voluntad, y a lo que da lugar es a una comunidad que se caracteriza precisamente por la soberanía. Es decir, por una voluntad que detenta la supremacía, que se impone. De esta manera, se reduce la participación en 
lo político a ejercer de alguna forma un acto de poder. Todo el objeto de la reflexión política consiste en la conquista, preservación y ejercicio del poder, en el diseño de sus límites y en cómo superar esos límites. Esto último no sólo ocurre si se piensa en los partidos políticos o en los representantes como sujeto de todas esas operaciones (conquista, ejercicio, preservación, etc.). También si se piensa en el individuo concreto como sujeto frente a sus propios representantes (o frente a los partidos políticos que intermedian entre ambos); en este caso, los contrapesos al poder, la división de poderes, los derechos individuales, etc., son también vistos como conquista, ejercicio y preservación del poder. En último término, si no hay más que un conflicto más o menos complejo de voluntades, se comprende que no se hable más que de poder. Todo lo cual muestra la imposibilidad de pensar en términos de verdadera comunidad porque no hay bienes que compartir. El poder, por su propia naturaleza, refleja el alcance de cada voluntad y en este sentido toda voluntad ajena es límite de la propia. Cuando los demás son límites es porque constituyen de nuevo una realidad distinta, ajena a mí, con quien sólo puede haber en el mejor de los casos coincidencia o compatibilidad, pero nunca verdadera comunidad.

\subsection{El tipo de razonamiento práctico}

La tercera diferencia tiene que ver con el tipo de razonamiento práctico que es propio de cada comprensión de la comunidad. Como el autor había señalado en un trabajo anterior, el desacuerdo fundamental sobre la naturaleza del bien que se da entre ambas concepciones de la comunidad, no es sólo teórico sino esencialmente práctico. Son concepciones rivales de la racionalidad práctica, de las relaciones de los seres humanos con el bien de sus acciones, de las reglas y virtudes prácticamente encarnadas que son específicas a cada concepción rival del bien. Esas concepciones sólo se confrontan decisivamente cuando se presentan tomando cuerpo en comunidades particulares. Es parte de la vida de familias, escuelas, hospitales, parroquias, vecindarios, lugares de trabajo; donde toma forma reconocible una particular concepción del bien. La indeterminación y empobrecimiento de la concepción basada en el interés público se ejemplifica en la propia realidad social (MacIntyre, 1990: 355-356).

En el caso de las estructuradas en torno al bien común, la pregunta nuclear es: ¿qué es mejor para mí, en cuanto miembro de tal comunidad, en esta situación particular? La pregunta política entonces es: ¿qué lugar ocupa el bien de cada una de las actividades del individuo en la vida de la comunidad política? Por eso, la pregunta por mi bien, en determinada actividad, no puede divergir de la pregunta por mi bien, en cuanto miembro de la comunidad política. La pregunta no es tanto qué es lo mejor para mí, ni siquiera qué debo hacer, sino qué debemos hacer. Porque se trata de un razonamiento en común (en ocasiones explícitamente juntos) donde la conclusión puede suponer acciones diferentes pero coordinadas (MacIntyre, 1994a: 31-32).

En un trabajo previo MacIntyre se pregunta cuáles son las creencias sustantivas, materiales, que debemos sostener si pretendemos ser agentes racionales prácticos e involucrarnos en genuinos debates racionales. A su juicio, que habitamos un género de comunidad en la que los participantes rivales del debate pueden ser tratados prima facie como dignos de confianza. Tal creencia se refuerza por la aceptación de una comunidad de normas sancionadoras. Con todo, una creencia compartida de este tipo, aunque necesaria, no es suficiente. Hace falta la pertenencia a una comunidad que comparte lealtad a alguna concepción total, tolerablemente específica del bien humano último. Sólo a la luz de tal entendimiento compartido los diferentes tipos de actividad e institución (cada uno con su bien o sus bienes subordinados) puede ordenarse en los términos del bien último. Existe así un estándar independiente de los deseos individuales o de los intereses de grupo (MacIntyre, 1991: 99).

En el ámbito recién señalado la justicia es dar reconocimiento debido y retribución a cada persona o institución según su contribución a la vida completa de la comunidad. Así se expresa en normas que gobiernan formas de relación humana, que especifican lo que cada participante en la relación le debe a otros. Pero la investigación racional sobre la justicia depende del acuerdo previo sobre la naturaleza del bien y más fundamentalmente en las creencias básicas que definen y comprenden tal bien. En 
definitiva, la suma de la creencia en ser dignos de confianza más las creencias compartidas sobre el bien (MacIntyre, 1991: 100).

En sociedades estructuradas por el interés público, el razonamiento práctico pretende responder a cuatro preguntas. (1) ¿Cómo deben, individuos y grupos, contribuir al sostenimiento de instituciones gubernamentales? (2) ¿Qué beneficios deben obtener, individuos y grupos, de la acción del gobierno? (3) ¿Qué garantías institucionales debe haber para asegurar los intereses, individuales y de grupo, de la interferencia del gobierno o de otro grupo? (4) ¿Cómo evitar que el gobierno sirva a intereses individuales o de grupo? Las respuestas parten de un esquema donde utilidad y derechos son centrales. Los actores se comprenden como maximizadores de utilidades en competición entre sí en un ambiente estable con expectativas racionales. Se institucionaliza la competición y el conflicto, aunque la manera de razonar será mediante la apelación a estándares impersonales e imparciales (MacIntyre, 1994a: 3334).

En mi opinión, la reducción de lo político, a aquello que resulta conveniente a la permanencia y crecimiento del sistema económico, podría inducir a pensar que en el fondo es verdad que toda política es mercantil. Sería mercantil en la medida en que la falta de participación, la distancia entre representante y representado y la ausencia de identidad nos recuerdan la relación mercantil: lo único que queremos es la obtención de un servicio o un bien que sea acorde con lo que pagamos o con lo que creemos que se nos debe. A mayores, si tenemos en cuenta que la distancia no es solamente la que se produce entre representante y representado. En efecto, se ha vuelto un lugar común señalar que las relaciones formales entre burocracia y ciudadanos no son intersubjetivas, no crean vínculos orgánicos sino asimétricos. En nuestras sociedades presentes, la racionalidad burocrática no crea mediación sino aislamiento y separación. Esta relación de dependencia reforzaría las identidades de sujeto dador y activo frente a objeto receptor y pasivo. De esta forma, los ciudadanos despolitizados degeneran en clientes que hacen demandas cada vez más grandes a un Estado que no puede satisfacerlas.

En la entraña de esta actitud, puede verse el origen de otro de los característicos peligros de nuestra política presente. En el fondo los ciudadanos están aceptando comportarse respecto a sus representantes como clientes. Si el representante se lo toma en serio, descubrirá que la manera de perpetuarse en el poder consiste precisamente en transformar a sus electores en clientes satisfechos. Para ello en la situación ideal se organiza un sistema a través del cual los ciudadanos obtienen un beneficio por nada. Y de igual modo el que gobierna emplea para ese beneficio lo que aportan otros grupos sociales o simplemente lo que obtiene a través de otros ingresos del Estado. Resulta así un sistema clientelar en el que en principio todos ganan. Los ciudadanos clientes apoyan sin dudarlo a su representante proveedor, que les colma sus posibilidades económicas privadas. Por su parte, el gobernante proveedor retiene así indefinidamente el poder (XX, 2017: 497-519 y las referencias allí citadas).

A mi juicio, la imposibilidad de generar un sentido del bien común con el modelo del individualismo posesivo en nuestra era técnica e industrial se pone de manifiesto ante la dificultad de enfrentar el clientelismo. En efecto, desde la perspectiva del principio de representación, no parece que pueda haber reproche moral alguno a la venta del voto. Todo lo más se puede criticar que dicha venta sea producto de la carencia de bienes básicos porque supone una merma de la autonomía del elector. Pero al carecerse de bien verdaderamente común, no hay un término por respecto al cual juzgar al elector. Por eso la pregunta que queda abierta y a la que el fenómeno clientelar nos interpela, es si tiene alguna relevancia para una comunidad política democrática cuáles sean los motivos que mueven a los electores. Aunque se desconozcan, sin embargo, cabe preguntarse si existen razones o motivos mejores que otros, e incluso si los hay indeseables.

MacIntyre sostiene además que en la sociedad presente el razonamiento práctico presenta importantes restricciones de tiempo y se enmarca en la enorme multiplicidad y heterogeneidad de las respuestas ajenas. Ante esta complejidad la decisión sólo es posible si se reduce todo a un grupo de reglas y generalizaciones breves y simplificadas (MacIntyre, 1994b: 59-61). Tales reglas abrevian y 
presuponen lo que es o se cree que es como conocimiento del rango de acuerdos sobre utilidad, derechos, contrato, en un contexto particular. Y en cada situación las reglas y generalizaciones son específicas al contexto. Por lo anterior, todo razonamiento práctico de este género es razonamiento en algún tipo particular de contexto, donde la especificidad está en las premisas de las que se parte (MacIntyre, 1994b: 66).

Tiempo atrás MacIntyre había señalado que en sociedades donde la moralidad se define independientemente del bien, la relación entre las diferentes reglas morales desaparece y el resultado es que las cuestiones morales se presentan como un paquete de problemas separados, aislados e irresolubles (MacIntyre, 1990: 354). En nuestras sociedades presentes, estructuradas a partir del interés general, respondemos a cada problema moral y social de manera fragmentada. Nunca la respuesta está informada por una concepción del tipo de comunidad que queremos y que reconozca la contribución peculiar de cada grupo social a la vida de la comunidad (MacIntyre, 1991: 107). Ahora bien, esta compartimentalización es sólo una señal de algo más profundo, como es un yo dividido. Porque nuestras comunidades contemporáneas se mueven entre dos realidades. En unos roles, se nos pide que pensemos y actuemos como individuos, con los propios deseos, preferencias, principios, cálculos, elecciones que rigen el obrar. Todos estos son propios de la vida económica, donde uno es competidor o consumidor. Y también de la vida política donde uno es candidato, elector, detentador de un cargo público o simple espectador. Al mismo tiempo, hay otras funciones y relaciones donde uno se dirige a los bienes comunes de familia, vecindario, lugar de trabajo; donde la pregunta es por cómo trabajamos juntos y como somos capaces de lograr nuestros bienes comunes y compartidos. Los individuos son extraños para sí mismos, el yo contemporáneo es un yo dividido (MacIntyre, 2008: 266-267).

\subsection{Los problemas más característicos}

En cuarto lugar, se plantea cuáles son los problemas más característicos de cada uno de los modelos. Las sociedades organizadas por el modelo del bien común tienen un problema endémico: siempre es objeto de debate cuál es el bien común aquí y ahora para esta determinada comunidad política. Es necesario un debate articulado y existen desacuerdos que son en ocasiones disruptivos. Por otro lado, cabe siempre el riesgo de identificar el bien común con el bien particular de quien gobierna y su imposición (MacIntyre, 1994a: 35).

En el caso de las comunidades articuladas por el interés público, hay que señalar que sostenerlo tiene un coste lo que lleva a preguntarse cómo se distribuye el coste y cómo se justifica tal distribución (MacIntyre, 1994a: 29). Además, por lo visto, al tratar cómo es el razonamiento práctico al interior de tal comunidad, se puede esperar que cada uno se pregunte si no podrá acceder a los beneficios que el interés público sostiene, pero sin los actos de contribuir a ellos. Se trata de lo que denomina el problema del free-rider. Este problema puede surgir en las sociedades estructuradas por el bien común, pero se tratará precisamente de quienes no razonan conforme al bien común y por tanto a su propio bien, mientras que el free-rider razona según el esquema del interés público (MacIntyre, 1994a: 3435).

Comparece aquí la cuestión de qué esperamos del gobernante. Si en el fondo estamos ante un problema de poder, de su conquista y preservación, en realidad permanecemos en el ámbito de los juegos de voluntades. Y la pregunta que se hace quien gobierna sigue firme: ¿por qué debo aceptar límites a mi voluntad? En el fondo no se aceptan, sino que se imponen. El por qué existen frenos al ejercicio del poder es algo que no termina de explicarse. O, mejor dicho, algo para lo cual se da una razón o justificación extrapolítica. Pero, vistas las cosas con perspectiva netamente política, lo único que debe hacer quien gobierna es imponer su voluntad. A fin de cuentas, es la pasión por imponer la propia voluntad lo que le ha llevado hasta allí y lo que le sostiene en su afán por permanecer. No debe extrañarnos entonces que emplee todos los métodos a su alcance para lograr su propósito porque todos son políticos en la medida en que son ejercicio del poder. En último término, las razones extrapolíticas que se plasman en el Derecho para limitar tal ejercicio de poder pueden seguir siendo vistas como otras voluntades que aspiran al poder en pugna con quien lo detenta. Seguiríamos así en el irresoluble 
conflicto de voluntades, en la medida en que no hay nada realmente al margen de éstas. La desconfianza hacia lo político de quienes no ejercen el poder es inevitable en este orden de cosas. Y parece inevitable la tendencia de quienes lo ejercen por sobrepasar las barreras extrapolíticas que se les ponen.

Por otro lado, MacIntyre señala que en tales comunidades se parte de una variedad de filosofías políticas rivales que no se ponen de acuerdo ni siquiera en los propios términos del debate, porque cada uno usa los suyos, aunque se presente como razonamiento según estándares imparciales. $\mathrm{Y}$ al mismo tiempo se excluye a quien niegue la racionalidad supuesta del marco de juego (MacIntyre, 1994a: 46).

Con anterioridad MacIntyre había desarrollado este problema. A su juicio, la concepción de los derechos característicamente invocada por quienes se ven envueltos en un conflicto de derechos, y los procedimientos retóricos empleados para avanzar en las propias pretensiones de derechos que toman cuerpo en tal concepción, son tales que invocarlos o emplearlos supone verse inmerso en un error. El idioma dominante y la retórica imperante de los derechos no pueden servir genuinamente a propósitos racionales y es mejor evitarlos. Porque para un debate racional sobre aplicación de la moral o de conceptos valorativos es necesario un estándar independiente de deseos, preferencias y voluntades de las partes contendientes al que apelar, y que pueda mostrar por qué las razones de un punto de vista son superiores al otro. Si falta tal estándar, nada diferencia a un supuesto debate racional o valorativo del mero choque de deseos, preferencias y voluntades. En ausencia de dicho estándar no habrá forma de valorar aquellas razones que uno se da a sí mismo para juzgar y obrar de modo particular (MacIntyre, 1991: 96-97).

Aún más, cada vez más asuntos entran en el terreno de lo discutible, se refuerza, a la vez, la tendencia a apelaciones a principios como deseos, preferencias y voluntades, y se hace necesario defenderse de la posibilidad de ser instrumento de tales deseos, preferencias y voluntades ajenas (MacIntyre, 1991: 100-101).

Por último, también ha señalado la dificultad de las sociedades estructuradas por el interés público en justificar la lealtad necesaria para que tal sociedad florezca, toda vez que se parte de un concepto individualista y minimalista de bien común (MacIntyre, 1997: 242). En efecto, en los estados contemporáneos, la lealtad de grupos heterogéneos puede retener acuerdos temporales cuando la carencia de tales acuerdos supone pagar un precio demasiado alto. Para eso, quienes gobiernan tienen que adoptar diferentes e incompatibles posiciones: unas veces en nombre de consideraciones de mercado, otras no: unas veces aceptando la responsabilidad por un aspecto de la vida social, otras no; unas veces por la tradición, otras por la modernización. Para eso hace falta una bolsa de valores variados de los que echar mano de uno ad hoc para cada situación. Ante el conflicto no hay un orden de principios al que apelar sino sólo el resultado de coaliciones de interés y de poder determinadas por las élites (MacIntyre, 1997: 245).

\subsection{El género de participación}

En quinto lugar, se puede hacer referencia al género de participación que es requerido por cada uno de los tipos de comunidad. Las sociedades articuladas en función del bien común requieren un consenso político grande y compartido sobre los bienes en general y sobre el bien común específicamente. Aunque pueda haber desacuerdo y debate, al menos se comparte el tipo de actividad que comparte acuerdo y desacuerdo. Lo anterior exige sociedades de tamaño pequeño (MacIntyre, 1994a: 36). Puede añadirse también que el grado de involucramiento necesario supondrá también una mayor visibilidad de la realidad política (MacIntyre, 1994a: 41).

Con todo, en un trabajo posterior ha señalado que, aunque una sociedad política informada por la noción de bien común requiere un alto grado de cultura compartida, sin embargo, es muy diferente a aquellas cuyos lazos esenciales son los de una tradición cultural compartida. Dicho de otro modo, una 
polis no es un Volk. La primera sólo se da si se comparte al menos una lengua, modos formales e informales de deliberación y un amplio grado de comprensión común de prácticas e instituciones. Esto deriva generalmente de una tradición cultural común, pero sirve siempre a los fines de una comunidad en la que los individuos son capaces de cuestionar a través de la deliberación común lo que se da por supuesto hasta el momento por la costumbre y la tradición sobre su bien y el bien de la comunidad. Una polis es una comunidad, potencial o actual, de auto-escrutinio, de indagación racional. Los lazos del Volk son pre y no racionales (MacIntyre, 1997: 241). Por eso mismo, el Volk no logra una lealtad política justificada (MacIntyre, 1997: 244).

Por el contrario, las comunidades organizadas en función del interés público presuponen que la participación amplia es imposible y no existe confianza en los demás. El diseño institucional es de distribución de costes y beneficios, asegurar la confianza y predictibilidad con independencia de la confianza personal. Las comunidades pequeñas se tratan como unidades que sirven a la unidad mayor. Además, ahora el conocimiento social es muy especializado (MacIntyre, 1994a: 37) y el involucramiento es menor lo que genera una política más opaca hasta el extremo de haber creado el concepto mismo de razón de Estado donde resulta moralmente buena la actuación de actores públicos que privadamente sería rechazable (MacIntyre, 1994a: 41).

A mi juicio, por lo visto hasta ahora, se entiende que la situación descrita genera la desafección de la vida política por parte de los ciudadanos. Principalmente porque tomar parte en lo político es participar en algo ajeno en lo otro. ¿Para qué voy a querer participar en algo que me resulta ajeno? No tiene sentido entrar en un ámbito donde no es posible encontrar la propia identidad. Es más, lo lógico es buscar a alguien que me represente. De este modo puedo dedicarme a ejercer el conjunto de libertades de la vida privada, donde me encuentro y me identifico, y entregar a otros los ámbitos de mi desinterés. No se trata de que ésta sea la causa de la aparición del principio de representación política, pero concuerda perfectamente con el sentido que se le da en el Estado moderno (Constant, 1989 [1819]: 268; 281-282). De nuevo, podemos observar que las tensiones entre representante y representado tienen difícil solución si el contenido de lo político es únicamente el poder. Buscamos a alguien que nos represente, pero damos por hecho que propiamente está ahí no tanto para eso cuanto para permanecer en el poder y ejercerlo.

Tenemos así el problema de la distancia entre representante y representado. Hay que preguntarse si en el fondo esa distancia es buscada por el propio representado quien carece de interés por sus libertades políticas más genuinas. En el modelo del individualismo posesivo no hay interés en la comunidad política (Macpherson, 2002 [1962]: 257-262). El ser humano es libertad, pero libertad para disponer de su persona y su propiedad de cara a las relaciones mercantiles: no hay interés en lo que hace el representante en la medida en que éste proteja esa manifestación concreta de la libertad individual.

Puede observarse la clásica dificultad de la falta de participación en la vida política por parte de los ciudadanos. Y es que, como consecuencia de lo anterior, no tiene sentido la participación en lo público. Porque en el modelo humano del individualismo posesivo no hay lugar relevante para otro uso de la libertad que no sea el que específicamente se refiere a las relaciones de cambio. En efecto, participar en lo público significa únicamente no poder ejercer las libertades privadas. Si todo lo social es solamente instrumento para el sostenimiento y crecimiento del sistema económico, las fuerzas individuales no deben servir a nada que no sea dicho sostenimiento y crecimiento (Polanyi, 2011 [1944]: 86-127). Se emplearán en lo político en la mínima medida posible. El principio de representación aparece como la mejor fórmula para dedicar ese mínimo imprescindible. La distancia entre representante y representado y la ausencia de participación política son coherentes con una sociedad de mercado.

\subsection{El modo de entender las virtudes}

En la tercera de las conferencias, MacIntyre desarrolla algunas diferencias más que se pueden añadir a las mencionadas. En sexto lugar hay que referirse al distinto modo de entender las virtudes. Para el 
modelo de comunidad estructurada en bienes comunes, es decir, para el modo aristotélico tomista de entender las virtudes, éstas son medios para lograr fines, es decir para alcanzar bienes, el bien común o el bien sin más. Pero al mismo tiempo son partes constitutivas de los fines a los que sirven y son valiosas por sí mismas. En la perspectiva de las sociedades modernas, estructuradas por el interés público, las virtudes son en realidad habilidades (skills) que sirven siempre a un fin y se valoran solamente como medios, es decir, son valorativamente neutrales (MacIntyre, 1994b: 71).

Además, para el modelo aristotélico la virtud pertenece a la persona y no a la función (MacIntyre, 1994b: 71). Por eso, la respuesta a qué vicios y virtudes tiene una persona es la misma a cómo esa persona ordena los bienes en sus actividades diarias. Es decir, se juzga, política y moralmente, las virtudes de uno como persona. Por eso, la vida familiar y de amistad se distingue de la vida política pero no es irrelevante. Y la educción moral se convierte en tarea de toda la comunidad (MacIntyre, 1994b: 74). Para el sentido moderno, la virtud lo es para la función más que para la persona y se adscribe a la persona en cuanto player (MacIntyre, 1994b: 71). Por eso, las habilidades son siempre específicas a cada contexto y el individuo debe reconocerlas en el área de su vida como tal o cual papel o función (MacIntyre, 1994b: 69-70). En cierto sentido la única habilidad que sirve para todo es la adaptabilidad para la eficacia y por eso no importa qué otras habilidades exhiban uno en otros contextos (MacIntyre, 1994b: 71).

Por lo anterior, para la perspectiva aristotélico-tomista, las virtudes en determinados contextos pueden ser ineficaces, al menos para los estándares modernos de eficacia.

\section{Utopía y realidad del bien común y el interés público}

Las anteriores diferencias indican ya cuál es el modelo de MacIntyre sostiene. Con todo, su defensa pasa todavía por dos aspectos más. En primer lugar, mostrar el carácter no utópico del modelo basado en el bien común. En segundo lugar, señalar las críticas al modelo basado en el interés público.

En efecto, la principal crítica que se puede hacer al planteamiento de MacIntyre es que pensar en una comunidad política aristotélica es irreal y utópico porque las estructuras de la sociedad moderna excluyen la posibilidad de comunidades y políticas locales. Responde que la ética y la Política aristotélica proveen de base racional para un modo distintivo y reiterado de actividad social, que se puede ejemplificar en prácticas pasadas y presentes y que son reflexivas y están articuladas por el bien común (MacIntyre, 1994b: 54). Hay experiencias de prácticas donde los participantes descubren razones para obrar que son reconocibles como buenas razones por quienes reconocen los bienes. Así, al compartir tales bienes y fines se ven envueltos en un tipo diferente de relación social. Al regenerar así una práctica, se crean organizaciones cooperativas que son una forma nueva de comunidad y los individuos deben plantearse y responder qué lugar ocupa tales bienes y fines en sus vidas. Se recrea una comunidad local y aparece un acuerdo significativo en dónde está la dirección del bien común, en el reconocimiento de las mismas cualidades intelectuales y morales como virtudes, y en la lealtad compartida a unas normas morales categóricas. En el fondo hay una tendencia ineliminable en todo orden social y cultural a alcanzar modos de autocomprensión aristotélicos (MacIntyre, 1994b: 55-57).

MacIntyre ha tratado de ser algo más propositivo en un trabajo posterior donde se pregunta en qué condiciones es posible una sociedad en la que los individuos aprendan sobre sus bienes individuales y comunes de modo que las preguntas sobre la justificación de la autoridad se respondan a través del debate y de la indagación racional. La respuesta a este interrogante aparece en muchos otros lugares de su obra. En efecto, se trata ante todo de una vida política (i) donde se reconozca la obediencia a la ley natural; (ii) donde la autoridad del derecho positivo derive de la ley natural y sea reconocida por la gente común; y (iii) esa misma gente comprenda que veracidad, respeto, paciencia, cuidado y mantenimiento de las promesas son requeridas para alcanzar a conocer lo necesario sobre el bien. Lo anterior requiere de las cuatro virtudes cardinales y se trata de una comprensión compartida de bienes, reglas y virtudes (MacIntyre, 1997: 247). 
Se da en contextos locales que la política contemporánea excluye. Se trataría de comunidades de pequeña escala, autosuficientes frente a las incursiones del Estado y del Mercado. Tales comunidades rehúsan la compartimentalización porque comparten visiones de lo virtuoso. Por eso, defienden la integridad frente a la adaptabilidad característica de la modernidad presente (MacIntyre, 1997: 248249).

Es en este orden de cosas donde, como en otras ocasiones, MacIntyre afirma no ser comunitarista. A su juicio, el comunitarismo no es un rechazo del liberalismo, sino sólo un diagnóstico de algunas de sus debilidades, al punto de que hay versiones liberales y comunitaristas que se complementan y no se contradicen. La comprensión comunitarista del bien común no es la que él ha descrito, aunque sólo sea porque el bien común y el bien individual se eluden en el planteamiento comunitarista (MacIntyre, 1997: 244, 246).

Frente a esto, es cierto que las agencias corporativas, públicas y privadas, del mundo presente marginalizan este tipo de prácticas, al menos de dos modos. Por un lado, la división del trabajo por la que cada uno realiza unas instrucciones específicas a una fase de la operación dejando a otros administrar el conjunto (MacIntyre, 1994b: 54). Años más tarde ha insistido en el problema de las élites y en la carencia de lugares en las sociedades políticas contemporáneas para el debate racional y la deliberación abiertos a todos en sus vidas diarias. Esto es la contraparte de la restricción del debate político a una élite privilegiada, que hace que el ciudadano común rara vez sea otra cosa que un espectador político (MacIntyre, 2008: 263). Por otro lado, el éxito en las sociedades modernas se mide primariamente y a veces sólo por la obtención de bienes externos a las prácticas (dinero, poder, estatus, reputación) y cuando los bienes externos se constituyen en fines de las actividades, estas dejan de ser prácticas en sentido aristotélico (MacIntyre, 1994b: 54).

Y es aquí donde aparecen las críticas más directas al modelo de sociedad propio de la modernidad. En efecto, en este se separa lo que cada uno toma por su fin individual y los fines de las prácticas en que uno participa. De esta forma todo bien se entiende en términos de bien de un particular individual, y bien es aquello que alguien valora como tal. Así, un idioma de preferencias e intereses no se entiende en términos de bienes compartidos sino de preferencias e intereses individuales y de grupo que a veces coinciden y a veces entran en conflicto (MacIntyre, 1994b: 55). Los derechos son ahora áreas exentas de intervención ajena. Los derechos se conectan cada vez más con los individuos qua individuos, concebidos tales individuos al margen de su rol social o de sus relaciones sociales. La multiplicación de pretensiones de derechos no sorprende si se reconoce la ausencia de cualquier forma compartida de justificación racional y de cualquier criterio compartido para identificar los derechos y su contenido (MacIntyre, 1991: 102, 104).

Por eso, parece como si las posibilidades de la modernidad política sólo se alcanzan si se rompe los lazos con la propia comunidad local. Ésta tiene que resistir la posibilidad de ser asimilada a la Política y la Economía del moderno Estado Nación. Los problemas del mismo son simplemente enunciados, pero se deducen de la caracterización del modelo de comunidad articulado desde el interés público: la profesionalización de lo político reducido a un asunto de élites, donde las masas quedan como clientes, votantes u objetos del management legislativo y administrador, quien a su vez establece las alternativas políticas posibles (MacIntyre, 1994b: 76). La relación con los gobernados se rige por las reglas de la relación de una multinacional con los consumidores. El Estado desarrolla un tipo de acción política antagonista de la local y autosuficiente. Al mismo tiempo, necesita recursos que sólo logra precisamente de las agencias gubernamentales y de las empresas. Frente a esto, una comunidad local requiere de resiliencia, inclinación a aprender de la propia historia, generosidad hacia los extraños y sabiduría práctica (o prudencia). El Estado moderno se rige en cambio por la ambición, la movilidad social y geográfica, la desigualdad económica, el avance tecnológico (MacIntyre, 1994b: 77-78).

Lo anterior es causa de la reaparición del fenómeno populista. Parece que es una de las posibles reacciones características de quien descubre que hay realidades que escapan a la decisión humana y no deberían. Otra cosa es que sea una respuesta satisfactoria o que genere males mayores que los que 
pretende evitar. Los enemigos del populismo, que se han hecho con esos ámbitos de la autonomía del individuo, se caracterizan precisamente por parecer anónimos. Más aún, ni siquiera se puede decir que respondan a personas concretas. No es posible aportar mucho más, porque en el mundo de las cosas humanas la posibilidad de previsión es pequeña: el populismo es una reacción posible, pero no necesaria. Representa una manifestación de queja, alarma, desengaño, frustración, desencanto, de sentirse engañado ante el estado de cosas. $\mathrm{Y}$ es que ese estado de cosas no parece coincidir con las promesas del hombre contemporáneo (Ionescu \& Gellner, 1969; Piccone, 1995: 81-142).

Por su parte, la llamada economía de mercado y sus efectos impiden las relaciones sociales necesarias. Las reglas que impone esta economía impiden a unos el trabajo, condena parte de la fuerza laboral de las sociedades menos desarrolladas y genera sociedades según intereses competitivos y antagonistas (MacIntyre, 1997: 249-250). En los trabajos más recientes ha insistido de nuevo en los problemas de la desigualdad económica. En efecto, al problema de la profesionalización de lo político se une la desigualdad de acceso y de influencia sobre los que toman las decisiones políticas. Tales desigualdades tienen sus raíces en las que hay respecto a los bienes y al poder económico. Incluso la educación prepara para aceptar una sociedad de desigualdades y no para la deliberación racional compartida sobre la vida y los bienes en común (MacIntyre, 2008: 263). Conforme crece la desigualdad el sentido de la inversión se dirige precisamente a maximizar la riqueza y el ingreso de una minoría cada vez menor. La desigualdad es efecto de la necesidad de maximizar el beneficio que empuja a las corporaciones públicas y privadas y a las agencias públicas a tratar a la población como fuerza de trabajo para ser empleada, desempleada o retirada antes o después. Es un tipo de economía que es enemiga y destructiva de una gran cantidad de proyectos vitales a través de los cuales los individuos y grupos buscan bienes individuales y comunes y su bien último. Es decir, las relaciones económicas impiden las relaciones necesarias para lograr el bien común (MacIntyre, 2008: 264-265).

\section{A modo de conclusión}

El extrañamiento de lo político, la sensación de fatalismo ante fuerzas incomprensibles, la percepción de pérdida de libertades, remite en último término a un abandono por parte del propio ser humano de ámbitos que no debería haber abandonado. Y que ahora no parece capaz de recuperar porque el tiempo se agota ante las exigencias de una vida económica incesante que siempre requiere más. Pareciera que los problemas de la representación solamente pueden superarse a través de una real y efectiva participación política. Sin embargo, la noción de autoconservación del individuo entendida como adaptación a las exigencias de pervivencia del sistema pone de manifiesto que tal participación es difícil, en la medida en que no sirve a este fin. Al contrario, participar en la vida política distrae al sujeto de la necesaria acomodación a la función económica que le viene fijada. Dicho de otro modo y con palabras más simples, la pregunta que cualquiera se hace ante el requerimiento a participar en lo político es simplemente cuándo. Y la respuesta inmediata es nunca, porque el tiempo necesario no existe. De nuevo, nos encontramos con que cada vez es más difícil pensar en términos de participación política, bien común, identidad compartida.

Esto explicaría también que nos resulte intolerable que la acción de quien ejerce el poder suponga de algún modo una pérdida de nuestras libertades privadas que consisten principalmente en nuestra autonomía económica. Por eso, lo peor que puede hacer quien gobierna es subir los impuestos, enriquecerse a costa del erario público, no lograr modificar el curso de la actividad económica cuando ésta genera desempleo o inflación, etc. En el fondo, lo que buscamos en nuestros representantes es un gestor (por acción o por omisión) de lo económico y nada más. De ahí, que los límites que le ponemos al poder político sean los recién descritos. Lo que ocurra en el ejercicio de este no nos importa mientras nos permita el máximo ejercicio de nuestra autonomía en lo privado. Por eso, hoy en día hablar de Política es cada vez más hablar de Economía. Es más, cuando parece escapar es para caer en manos de la comunicación reconvertida pura y simplemente en marketing, es decir, en venta. De la misma manera, se explica la actual profesionalización de lo político. Se trata de un problema de gestión, palabra característica del mundo empresarial. Pero estamos ante una realidad meramente 
técnica. Se requieren gestores económicos que sean capaces de permitirme maximizar en la medida de lo posible mis libertades económicas privadas.

\section{Referencias}

Bobbio, N. (1979). Il positivismo giuridico. Giappichelli. Torino.

Constant, B. [1819] (1989). De la libertad de los antiguos comparada con la de los modernos (Conferencia pronunciada en el Ateneo de París, febrero de 1819). Escritos Políticos. Estudio preliminar. Traducción y notas de M. L. Sánchez Mejía. Centro de Estudios Constitucionales. Madrid.

Cruz Prados, A. (2009). Filosofía Política. Eunsa. Pamplona.

Hobbes, T. [1651] (2014). Leviathan. Clarendon. Oxford.

Horkheimer, M. [1947] (1973). Crítica de la razón instrumental. Traducción de H. A. Murena y D. J. Vogelmann. Sur. Buenos Aires.

Horkheimer, M. [1944] (2009). Dialéctica de la Ilustración (1944). Traducción de Juan José Sánchez. Trotta. Madrid.

Ionescu, G. \& Gellner, E. (eds.). (1969). Populism. Its meanings and national characteristics. Weidenfeld \& Nicholson. London.

MacIntyre, A. (1990). The Privatization of Good: An Inaugural Lecture. Review of Politics. 52. 344361.

MacIntyre, A. (1991). Community, Law and the Idiom and Rhetoric of Rights. Listening: Journal of Religion and Culture. 26. 96-110.

MacIntyre, A. (1994a). Natural law against the nation-state: or the possibility of the common good against the actuality of the public interest. Laws, Goods and Virtues: Medieval Resources for Modern Conflicts. Agnes Cuming Lectures in Philosophy. University College. Dublin.

MacIntyre, A. (1994b). The Virtues of Practice Against the Efficiency of Institutions. Laws, Goods and Virtues: Medieval Resources for Modern Conflicts. Agnes Cuming Lectures in Philosophy. University College. Dublin.

MacIntyre, A. (1996). Natural Law as Subversive: The Case of Aquinas. Journal of Medieval and Early Modern Studies. 26. 61-83.

MacIntyre, A. (1997). Philosophy, Politics and the Common Good. Studi Perugini. 3. 235-252.

MacIntyre, A. (2008). What More Need to Be Said? A Beginning, Although Only a Beginning, at Saying It. Analyse \& Kritik. 30. 261-276.

Macpherson, C. B. [1962] (2005). La teoría política del individualismo posesivo. Traducción de J. R. Capella. Trotta. Madrid.

Piccone, Paul. (1995). Postmodern Populism. Telos. 103. 81-142.

Polanyi, K. [1944] (2011). La gran transformación. Traducción de Eduardo Suárez. Fondo de Cultura Económica. México. 
Ramis, B. R. (2012). Derecho natural, historia y razones para actuar: la contribución de Alasdair MacIntyre al pensamiento jurídico. Dykinson.

Spaemann, R. (1980). Crítica de las Utopías Políticas. Eunsa. Pamplona. 